\section{Association Between Aplastic Anemia and Atrial Fibrillation: Is Inflammation the Only Underlying Mechanism?}

\section{To the Editor:}

We read with great interest the recent article about the relationship between aplastic anemia and atrial fibrillation (AF). ${ }^{1}$ It was reported that the incidence rate of AF was significantly higher in patients with aplastic anemia than in both the general population and a propensity score-matched control group. Underlying inflammation is suggested as the main cause of the association between AF and aplastic anemia.

Patients with aplastic anemia frequently need transfusion of blood products. Although it is predominantly reported in patients undergoing cardiac surgery; blood transfusion is related to increased incidence of new-onset AF. Blood transfusion induces inflammation and inflammatory markers such as bactericidal/permeability increasing protein levels are elevated after transfusion. Increased right atrial pressure as a consequence of volume overload, undetected myocardial damage and stimulation of inflammation are the suspected mechanisms of AF development after transfusion.,3 Repeated blood transfusion causes iron overload, and excessive iron accumulation in the myocardium leads several cardiac manifestations. Iron ordinarily starts to accumulate firstly in the ventricular myocardium and the atrial myocardium is affected later than the ventricles. Arrhythmia is the usual presentation of cardiac involvement and $\mathrm{AF}$ is the most common arrhythmia in these patients.
Iron has proarrhythmic effects on its own besides causing cardiac dysfunction from accumulation in the myocardium. ${ }^{4}$ Iron chelation treatment and phlebotomy restores cardiac function and can resolve arrhythmias in patients with iron overload. 5

In the reported study, transfusion data and ferritin levels of the patients are not assessed. Inflammation may play a role in both aplastic anemia and AF, of course, but as mentioned above recurrent transfusion episodes and related iron overload can also explain the increased incidence of AF in patients with aplastic anemia.

\section{References}

1. Hu WS, Sung FC, Lin CL. Aplastic anemia and risk of incident atrial fibrillation: A nationwide cohort study. Circ J 2018; 82: $1279-1285$.

2. Alameddine AK, Visintainer P, Alimov VK, Rousou JA. Blood transfusion and the risk of atrial fibrillation after cardiac surgery. J Card Surg 2014; 29: 593-599.

3. Fransen E, Maessen J, Dentener M, Senden N, Buurman W. Impact of blood transfusions on inflammatory mediator release in patients undergoing cardiac surgery. Chest 1999; 116: $1233-$ 1239.

4. Gujja P, Rosing DR, Tripodi DJ, Shizukuda Y. Iron overload cardiomyopathy: Better understanding of an increasing disorder. J Am Coll Cardiol 2010; 56: 1001-1012.

5. Zacharski LR, McKernan L, Metzger ME, Malone MG, Samnotra V, Bhargava A, et al. Remission of paroxysmal atrial fibrillation with iron reduction in haemophilia A. Haemophilia 2010; 16: 726-730.

Yusuf Ziya Şener, MD

Metin Okşul, MD

Cem Çöteli, MD

Department of Cardiology, Faculty of Medicine, Hacettepe University, Ankara, Turkey

Received June 3, 2018; accepted June 27, 2018; released online July 18, 2018

Mailing address: Yusuf Ziya Şener, MD, Department of Cardiology, Faculty of Medicine, Hacettepe University, Sihhiye/Ankara, Ankara 06320, Turkey. E-mail: yzsener@yahoo.com.tr

ISSN-1346-9843 All rights are reserved to the Japanese Circulation Society. For permissions, please e-mail: cj@j-circ.or.jp 